\title{
Art therapy after stroke: evidence and a need for further research
}

Frances Reynolds

\section{Introduction}

Long-term disabling conditions threaten a person's identity and well-being in many ways, through loss of function and discomforting symptoms, changes in roles and occupations, altered social relationships, and a disquietening sense of liminality (Hammel, 2006). There is limited but increasing research into the benefits of creative arts therapies (including art, music, dance and movement, and drama) for people living with various long-term physical conditions, but stroke has largely been neglected (Michaels, 2007) . This paper explores evidence regarding the contribution of visual art therapy to the rehabilitation of stroke survivors.

Medical art therapy may be regarded as a 'complex intervention' (Campbell et al, 2000; Redfern, McKevitt, \& Wolfe, 2006), as it comprises a multi-faceted array of therapeutic components. In the context of neurorehabilitation, each component appears to have great potential to address the functional, emotional and cognitive needs of stroke survivors. It is a form of nonverbal psychotherapy that results in both client and therapist having a tangible object to explore together. Such tangible objects offer powerful confirmation of the existence of the client. Creative self-expression may help the client to make contact with disturbing emotions in oblique ways that by-pass internal defenses and self-editing processes (Dekker, 1996). Given the profound and sudden loss of function that commonly follows a stroke, and the relatively high incidence of depression that affects about one third of stroke survivors (Hackett, Yapa, Parag, \& Anderson, 2005), self-expression through visual media may have much therapeutic potential.

Art-making as a therapeutic process offers diverse experiences (including kinaestheticsensory, expressive, cognitive and creative aspects) and may even influence physiological 
and neurological functioning (Hass-Cohen, 2008; Long, 2004). Emotional expression, particularly at the non-verbal symbolic level, is recognized as an important element of all creative arts therapies (Long, 2004; Malchiodi, 1999; Sell \& Murrey, 2006). It may therefore be a particularly helpful outlet for the $20 \%$ of people who are left with long-term speech and language impairments following stroke (Pedersen et al., 1995).

Art therapy is thought to help participants to gain insight into the psychosocial consequences of their disabling condition, to express their feelings about change and loss, and to make known their wishes for the future. Changes that are created in the art image may help to enhance perceived control and transform feelings about self and illness (McNiff, 1992). Creative arts therapies also offer empowering experiences for people who are otherwise faced with profound powerlessness, not only associated with illness and disability but with medical treatments, the patient role, and altered social relationships. The choices experienced when engaging in creative arts therapies 'contribute to feelings of autonomy and dignity when other aspects of life seem out of control' (Malchiodi, 1999; p16). Furthermore, the person may reclaim aspects of self and identity through their creative self-expression, finding it possible 'unfold the cramped self, uncover losses and strengths, and gain the courage to begin a process of reclamation of story and life' (Ferris \& Stein 2002, p.47). Identity loss is now being recognised as a great challenge for stroke survivors (Ellis-Hill, Payne and Ward, 2000), and the contribution of art therapy to identity reclamation and transformation is an important issue to explore.

In addition to its deeply expressive and coping functions, creative arts therapies offer the opportunity to move away from illness-related preoccupations to enjoy the 'life-affirming pleasures of making art' (American Art Therapy Association, quoted by Jones, 2004; p23). Although there tends to be a focus on process rather than product in the creative arts 
therapies, participants may nonetheless derive great satisfaction and self-esteem from witnessing the quality of their artwork and gaining positive feedback from others (Sell \& Murrey, 2004). Given that loss of occupations and meaningful activities reduce life satisfaction post-stroke (Hartman-Maeir, Soroker, Ring, Avni, \& Katz, 2007), art therapy may have great potential for helping stroke survivors manifest their preserved skills and develop new ones.

Through the skilful presence of the art therapist, the art therapy experience may be regarded as distinct from art practiced in other contexts (such as community groups or as a solitary leisure occupation). The therapist is important for providing emotional containment and a safe space in which to explore difficult, perhaps shameful, experiences (Malchiodi, 2003; Schaverian, 1991). This is a relevant issue as some stroke survivors' report feeling ashamed by their disabilities and altered selves (Dowswell, Lawler, Dowswell, Young, Forster, \& Hearn, 2000). Such feelings can be difficult to disclose for fear of burdening others, or disclosing vulnerability, and art therapy might offer a means of acknowledging and working through such difficult thoughts and feelings. Whilst there are sound reasons for anticipating that art therapy may meet the diverse needs of stroke survivors, a review of evidence was sought to establish whether these expectations are justified.

\section{Art therapy and stroke}

Although evidence has been collated about the benefits of art therapy (Slayton, D'Archer \& Kaplan, 2010) and therapeutic art-making (Perruzza \& Kinsella, 2010) for people living with many different health problems, stroke has been neglected. This review seeks evidence regarding the therapeutic benefits of visual art therapy for stroke survivors.

For this review, a search of literature was conducted using the search terms 'art' or 'art therapy' in combination with 'stroke'. Although further searching with additional terms such 
as 'outcomes', 'treatment outcomes' or 'effectiveness' was considered, the initial search process revealed so little evidence that further narrowing was unnecessary. A further search was conducted replacing 'stroke' with the search term 'traumatic brain injury' (TBI) to determine whether there were additional relevant studies. This is because people share certain experiences following stroke and TBI, such as sudden ‘biographical disruption’ (Bury, 1982), lack of psychological preparation, long-term disabilities, uncertainty about recovery, and identity threat. The databases PsycInfo, CINAHL, and Academic Search Complete were searched, followed by a search of Google Scholar to check whether additional material could be located. Some further references were taken from retrieved articles.

Following this search process, a number of articles and chapters were excluded. This included the article by Sacchett, Byng, Marshall, \& Pound (1999) that was discussed in the review by Slayton et al (2010). Although concerned with stroke survivors, this study was ultimately excluded as it focused upon the benefits of a directed drawing technique on the comprehension and naming skills of people affected by severe aphasia following stroke, rather than documenting the benefits of using art as a form of psychotherapy. Some of the located articles, books and book chapters were excluded because they described the ways in which stroke affects the artistic style of visual artists (e.g. Annoni et al 2005; Bäzner \& Hennerici, 2006; Bäzner \& Hennerici, 2007) or the use of art assessments with stroke patients to identify perceptual or other cognitive deficits (e.g. Sandburg, Silver \& Vilstrup, 1984; Silver 1975) or to identify emotional disturbances (Silver 2002). This material has not been included here as the objective was to review the therapeutic benefits of engaging in art therapy for stroke survivors (as reported by therapists or by survivors themselves). 


\section{Review}

The evidence located, whilst very limited, suggests that art therapy may address multiple objectives with people affected by stroke and other trauma to the brain (Barker \& Brunk, 1991; Wald, 1999). As with art therapy practiced in other contexts (Perruzza \& Kinsella 2010), its psycho-social objectives for stroke survivors include facilitating emotional processing and self-insight, social support, perceptions of control, and identity transformation. Art therapy has been described as helping stroke survivors to experience "renewed purpose and joy in living" (Wald, 1999; p.41). Unlike most descriptions of art therapy with people affected by other illnesses and disabling conditions, authors report its value for promoting stroke survivors' skills of physical coordination, attentional control, language recovery and visuo-spatial processing (Kim, Kim, Lee, \& Chun, 2008; Wald 1999). Clay work is presented as having particular therapeutic value for stroke survivors, in terms of promoting visuo-motor skills (Yaretzky \& Levinson, 1996; Leonard 1993).

The use of art therapy to address multiple objectives was illustrated in a case study by Wilson (2001). The case patient, David, was 65 years old. His stroke had affected the right side of his body, so forcing the use of the non-dominant hand. It had also resulted in expressive aphasia and attentional difficulties. David was receiving regular occupational therapy, physiotherapy and speech and language therapy, in addition to art therapy. Wilson noticed that David sustained attention for longer whilst drawing during art therapy. Cognitive benefits ensued, such as improved attention, sequencing, planning and integration of form, as shown by the improving organization of images over the whole page and their more recognizable content. In common with other stroke survivors (as reviewed later in this paper), David also used his drawings to express his feelings. The art therapist observed how he responded intensely to a child-like drawing of a human figure, likening the image to his wife, and seemingly accessing memories and feelings that had been unavailable up to that point. The therapist considered 
this to be 'a pivotal event in his psychological recovery' (Wilson, 2001; p.46). Whilst this specific emotional experience clearly occurred within art therapy, the multi-faceted contributions of the multi-professional rehabilitation program to his progress could not be isolated. Inter-relationships between the client's cognitive and emotional functioning were not clarified.

Yaretsky and Levinson (1996) used a form of art therapy to promote functional rehabilitation, as well as social interaction, in a group of hospitalized older people. The group met over a course of 5 weekly meetings and engaged in clay-work. Three of the group members were stroke survivors. The therapy included themes of home, assisting in patients' self-expression of feelings about their discharge from hospital. The authors noted how participants increasingly used their stroke-affected limb over the course of the therapy, and engaged in more social interaction. Longer-term benefits were not assessed, although the most of the participants expressed enjoyment of the group.

A further case study in which art therapy was used primarily to address cognitive deficits after stroke was described by Kim et al (2008). A 59 year old woman, who had experienced a stroke one year previously, took part in art therapy alongside other forms of rehabilitation. Assessment revealed the client to have multiple cognitive deficits as well as difficulties in movement. Goals for art therapy primarily addressed cognitive domains of functioning, being described as "improving spatial perception capability, color recognition, shape recognition, size comparison of objects, induction of expressed internal emotion, and improved socialization" (Kim et al, 2008; p.130). The art therapy process appeared directed by the therapist, who encouraged the client to draw familiar images such as tree, house, self, and family. Over time, the drawings revealed improvements in spatial awareness, symmetry, and manipulation of shape. In addition, the client also appeared to express herself symbolically 
through drawing, although limited examples were given. The client's attention, memory and conceptualization are said to have improved over time, as did various measures relating to movement and upper limb function. The authors described the art therapy experience as highly motivating. They thought that it was likely to have been responsible for the changes seen in the client, as previous rehabilitation programs (that lacked art therapy) had not resulted in clear improvements. Nevertheless, it remains uncertain whether the gains described could be attributed specifically to art therapy rather than to the other aspects of the rehabilitation program, or even the passage of time itself.

Horovitz (2005) presented an account of art therapy that addressed functional rehabilitation objectives as well as emotional recovery post-stroke. This account revealed a complex intertwining of therapeutic benefits, and also, like Kim et al (2008), difficulties in isolating the effects of art therapy within a multi-professional rehabilitation program. The case study concerned Bob, a 71 year old man who had experienced a left hemisphere stroke four years previously. This had left him with right side hemiparesis, expressive aphasia and severe apraxia (disordered movement). The objectives of art therapy included improving his expressive language, increasing his self-esteem and enabling him to express his emotional responses to the stroke. In some of his early artwork, the patient appeared to express feelings about his loss of function in nonverbal symbolic terms, through for example, presenting a figure with no hands, feet or ears. Art seemed to open up new ways of being for Bob, enabling identity transformation. He engaged in art therapy for three and half years and began creating art at home, acquiring progressively higher levels of skill. Bob drew much selfesteem from having his artwork framed and displayed in the clinic. Horovitz suggested that the support of the art therapy group as well as the art therapist helped to facilitate these transformational changes, together with the input of a speech and language therapist. The author also described the considerable benefits of art therapy for other patients living with 
aphasia following stroke. Many had flourished creatively, and had developed artistic skills despite having little or no interest in art before their stroke.

Further case examples have primarily illuminated the ways in which art therapy facilitates self-expression of deep-seated negative feelings, leading to self-insight and improved adjustment to the consequences of stroke. The benefits of art therapy for assisting expression of anger, loss and abandonment was described in a case study of a 57 year old stroke patient by Carmi \& Mashiah (1996). Nonetheless, communication may not solely discharge negative feelings. A creative arts program for frail older people was described by Johnson \& SullivanMarx (2006). These authors provided a brief case example of an older woman living with high levels of frustration associated with expressive aphasia and paralysis of her dominant hand following a stroke. In art therapy, the client was said to have felt able to express herself positively through her use of color and to have enjoyed the recognition of her artistic abilities by family and centre staff. She also experienced choice, the positive enjoyment of absorbing attention to color, and mutual social support within the art group.

Wald (1999) suggested that visual expression may release the frustration of verbal communication difficulties which commonly follow on from stroke, enabling emotional expression, as well as contributing to a more positive identity. However, she noted that righthemisphere lesions may result in disorganized artwork, attentional neglect and problems with spatial relationships. Although some of her clients used their artwork to work through personal experiences of disability post-stroke (for example, by creating a 'lop-sided' clay figure), Wald identified benefits beyond emotional expression and catharsis. More 'everyday' pleasures of art-making included clients taking pride in exhibiting their artwork, experiencing autonomy through suggesting artistic themes for the whole group to explore, enjoying humour and sharing within the art therapy group, and gaining a sense of purpose. 
The self-expressive potential of art therapy for people living after TBI was documented by case studies presented by Sell \& Murrey (2006), and these have relevance to stroke survivors. One client used her art therapy to communicate her frustration and powerlessness at not being able to visit her family at home. Another patient used the symbolic imagery of a fire to explore the aggressive impulses that had recently culminated in her committing a violent assault. These, and the other TBI patients described in the short vignettes, appeared to gain self-insight into their troubling emotions and behaviors, through the art therapy process. However, the role of the therapist in collaborative meaning-making during the art-making process was left somewhat uncertain. These authors noted that when working with clients in medical art therapy, there is a need to address their fears of looking 'stupid' or inadequate, linked for example, to memories of not performing well in art classes at school as well as self-consciousness about their current disabilities. Genser (1985) and Wald (1999) made a similar point, suggesting that for clients coping with functional difficulties after stroke, artmaking may be facilitated in the early stages of therapy by providing more easily manipulated materials such as collage.

The use of art to facilitate communication post-stroke was also described by Moon (2009), with a much younger client than seen elsewhere in the literature. The case study concerned a 16 year old (named as TR) affected by a small stroke that had paralyzed half of his face. The young man had many psychosocial difficulties, and had lived in a number of foster homes and psychiatric hospitals. Moon found TR to be uncommunicative in therapy and used painting to express his own frustration with the client. The author suggested that his honest artistic response enabled TR to begin communicating both verbally and also with his own imagery, and that this mutual focus assisted the forming of a more effective therapeutic relationship. It may feel much safer to explore the meanings of visual imagery than to offer 
explicit self-disclosure (Schaverian, 1989). According to Moon (2009; p147), “The arts evoke and intensify feelings while providing safe, concrete structures for their expression".

A more detailed case study of a stroke patient attending art therapy as part of a stroke rehabilitation program was presented by Gonen and Soroker (2000). Like several other studies reviewed so far, these authors presented art therapy as addressing multiple objectives with stroke survivors. Over a course of 20 sessions, the objectives were to promote selfawareness of disabilities, address negative emotions such as depression, increase motivation for rehabilitation, promote social relationships, and help establish new recreational opportunities. Patients mostly started attending the program early on in the rehabilitation process, from about one month after their stroke. The case study selected by the authors referred to a 51 year old man who had suffered a stroke in the right hemisphere, which had mainly affected the left upper limb. Moreover, he also suffered from severe complications of diabetes, which were thought to jeopardize the likelihood of successful rehabilitation. In the early stages of art therapy, he expressed his need for control through his choice of "nonmessy' art media. The authors interpreted his early artwork as symbolizing 'stuckness'. The authors observed that over time, the client explored identity change through his artwork. For example, he created two plasticine models of animals which he referred to as "me in the past" and "me at present".

As the art therapy program continued, the patient gained more access to his feelings, revealed by his increasing willingness to work in a looser, more colorful way. A number of artistic tasks were presented to help him explore and express his feelings about his current situation, his family relationships, his sense of control, and the changes and losses that he had experienced. These experiences were described as helping the patient to address his anxieties more openly, including 'his sense of being less of a person' since his stroke (Gonen and 
Soroker, 2000; p.44). The authors commented that some of his expressed feelings were considered too challenging for the art therapy group to process and that the therapist needed to offer containment at times. As the client became more able to express his emotions, he used bolder color and less controllable media such as watercolor. In terms of critical evaluation, as with other case studies, the selection of evidence was controlled by the authors, and the patient's own interpretations were unavailable. Although the authors regarded the patient's self-awareness of identity change and disclosure of distressing emotions as helpful for coming to terms with stroke and for gaining support, it remains unclear to what extent such openness assisted the patient in the long-term to adjust to his situation. The authors observed that the benefits of the art therapy were difficult to disentangle from the group's support and its possible function as an empathic surrogate family.

Although individual case studies are illuminating, formal research is very limited concerning the experiences of art therapy among people with neurological conditions such as stroke. Where conducted, such research tends to evaluate therapeutic art-making rather than formal art therapy. For example, Symons, Clark, Williams, Hansen, and Orpin (2011) presented a qualitative study of a visual art program offered by occupational therapists (rather than qualified art therapists) to out-patients with neurological conditions. Semi-structured interviews were followed by thematic analysis following recognized guidelines. Of the nine participants, three were living with stroke. Participants described the art-making process as helping them to recover function, for example in the upper limb. Although two of the three participants with stroke were disappointed at their progress in using the affected limb, they both described making valuable adaptations in order to be able to continue with their artmaking, including switching to the non-dominant hand, and accommodating to their limited motor control by adapting their painting style. It appeared that their motivation for art-making encouraged these adaptations. Further evidence is needed regarding whether these 
adaptational skills were transferred to other everyday activities, improving quality of life. Going beyond functional skills, a participant affected by stroke commented on how the art group offered a sense of belonging. Others reflected that their developing artistic interests were helping them to participate in the wider community. The pleasure of learning new skills, self-acceptance, and optimism about future were also described. During art-making, deep absorption and experiences of flow (as described by Csikszentmihalyi, 1996) were experienced by some participants. One woman who was living with stroke suggested that during art-making, her disabilities were less to the forefront of her awareness. "It gives me a good sense of freedom within my lack of capabilities. There's a freedom to create in there" (Symons et al, 2011; p.48). Participants described many positive aspects of the experience such as fun, confidence and success. Some believed that they were developing a positive identity as a person with artistic interests, with the potential to do something new in their lives despite their stroke or other conditions. They perceived this new occupation as helping them to resist being defined by their disabilities.

Although the study by Symons et al (2011) is limited by small sample size (especially in respect to the numbers of participants affected by stroke) and sample attrition in the followup interviews, the study is valuable for offering insights into stroke survivors' own experiences of engaging in a therapeutic art program. Such personal accounts are missing from the case studies reported above. However, it remains uncertain whether the patients who opted out of the later interviews found less benefit in art therapy. As a further limitation, it is also uncertain whether person-centered arts activities conducted by occupational therapists have the same degree of emotional intensity and self-exploration as those conducted by qualified art therapists. 
Finally, a study by Beesley, White, Alston, Sweetapple, and Pollack (2011) explored the meanings of participation in a creative arts program among a small group of stroke survivors. This program was conducted by a fine arts graduate together with staff from a community stroke team. Thus this was not art therapy per se but a therapeutic arts experience. Focus group discussions and interviews were analyzed following grounded theory guidelines, with appropriate safeguards that promoted rigor. The stroke participants were positive about many aspects of the art experience. They appreciated the self-expressive aspects of art-making, including the personal insights gained from documenting their journey through stroke. Some described improvements in their cognitive skills and language, and expressed satisfaction with their progress, especially from working alongside others who were more disabled. However, using the stroke-affected limb was experienced as a struggle by some of those taking part. The social context of the art group was appreciated for its support and encouragement. The study followed recognized qualitative research processes but nevertheless had a small sample, and generalization is uncertain. The longer term impact of participation in the art group on stroke survivors' confidence, quality of life and ongoing artistic interests would have been interesting to evaluate.

\section{Conclusions}

On the basis of the very limited evidence available, art therapy appears to provide multiple benefits to stroke survivors. A number of case examples and qualitative evaluations of therapeutic art groups suggest that art therapy may help stroke survivors to recover aspects of their cognitive functioning, such as attention, spatial processing, sequencing and planning (Kim et al, 2008; Wilson, 2001). Art therapy may also offer experiences of intense absorption which encourage persistent effort, leading to improvements in physical functioning such as using the stroke-affected limb or adapting to using the non-dominant hand (Symons et al, 2011; Yaretsky \& Levinson, 1996). However, some stroke survivors experience continuing 
frustration in using the stroke-affected hand in their art-making (Beesley et al, 201). Several studies have reported that art therapy promotes increases in social interaction and social recognition of the stroke survivors' artistic abilities and competence (Beesley et al, 2011; Johnson \& Sullivan-Marx, 2006; Kim et al, 2008; Symons et al, 2011; Yaretsky \& Levinson, 1996). Emotional benefits include the experiences of pleasure, challenge, achievement, freedom and flow, as well as taking pride in developing artistic skills and artwork (Beesley et al, 2011; Horovitz, 2005; Johnson \& Sullivan-Marx, 2006; Symons et al, 20011; Wald, 1999). Another recurring finding is that art therapy enables stroke survivors to express their concerns symbolically, discharging feelings of anger, loss and abandonment, and achieving new insights (Beesley, et al 2011; Carmi \& Mashiah, 1996; Gonen \& Soroker 2000; Horovitz, 2005; Kim et al, 2008; Moon 2009; Sell \& Murrey, 2006; Wald 1999; Wilson, 2001).

\section{Critical evaluation}

Many of the articles and chapters that were found through the search process described above primarily offered guidelines to art therapists for working with stroke patients and people affected by other neurological conditions (e.g. Sell \& Murrey, 2004; Wald, 1989; Wald, 1999), and only brief case examples were included to illustrate the outcomes of art therapy. These case examples are interesting, idiographic in nature, and offer glimpses of the therapeutic potential of art therapy. However, they may be considered to provide rather anecdotal evidence that is open to selection by the authors themselves. It cannot be ascertained whether the selected clients had responded in a particularly favorable way to art therapy, or not. The case examples cannot be considered as robust evidence by either quantitative or qualitative formal research standards. In terms of understanding stroke survivors' own perspectives, the very few qualitative studies that are available have been 
limited by small samples, and they have focused on therapeutic arts interventions conducted by professionals other than art therapists, rather than psychotherapeutic art therapy.

There seems to be no consensus about the optimal timing of art therapy for stroke survivors, with some studies describing art therapy within the first few months (e.g. Gonen \& Soroker, 2000) and others reporting interventions that were offered to clients much later (e.g. Horovitz, 2005, reported work with a client who was 4 years post-stroke). Some case studies refer to hospitalized patients (e.g. Yaretsky \& Levinson, 1996) whilst others describe therapy in a community setting (e.g. Horovitz, 2005; Johnson \& Sullivan-Marx, 2006). Studies have not isolated the specific effects of art therapy from other co-occurring interventions in multidisciplinary rehabilitation programs (e.g. Horovitz, 2005; Kim et al, 2008; Wilson, 2001). The social context of art therapy has been acknowledged as a potentially important element of the art therapy experience (e.g. Beesley et al, 2011; Gonen \& Soroker, 2000; Horovitz, 2005; Wald, 1999) and needs further enquiry. Reasons for stroke survivors dropping out of art therapy have been offered by some authors (e.g. Beeseley et al, 2011; Yaretsky \& Levinson, 1996) but further information about attrition processes might be helpful for assessing the outcomes of this therapy for stroke survivors, and identifying patients who may be best suited to this type of intervention. Although some authors (e.g. Horovitz, 2005; Symons et al, 2011), suggest that stroke survivors may take up artistic pursuits in the longerterm after their art therapy (with positive consequences for identity transformation and community reintegration), follow-up studies are lacking.

\section{Suggestions for further research}

Complex interventions, such as art therapy, that comprise multiple active components require well-designed multi-method evaluations. Ideally, these would combine both quantitative and qualitative approaches, to explore not only the outcomes of therapy but the processes through 
which clients experience change in their emotional, cognitive and physical state.

Standardized quantitative measures would be helpful for assessing how much improvement in functional skills and levels of well-being are gained through art therapy and for what proportion of participants. For example, the SF36 might be used to assess whether there are improvements in quality of life domains such as physical functioning, vitality and mental health among stroke survivors who complete a course of art therapy. Quantitative assessments of changes in self-efficacy and stroke impact might also be considered, using scales such as the Stroke Self-Efficacy Questionnaire (Jones and Partridge, 2008), or the Stroke Impact Scale (Duncan, et al, 1999). More formal pre- and post-test research designs would be advantageous, including control groups, which could help isolate the specific therapeutic benefits that can be attributed to art therapy over and above the positive social influence of fellow stroke survivors. Nonetheless, such designs may be considered antithetical to the person-centered or psychodynamic values of some art therapists. In any case, control groups raise ethical issues in therapy evaluation studies, and waiting list control groups may not be appropriate in the stroke context where early intervention is thought to be more effective (Paolucci, Antonucci, Grasso, Morelli, Troisi, Coiro, \& Bragoni, 2000).

All of the findings described in the review above need further detailed evidence, in particular to understand individual differences in clients' responses to art therapy, and qualitative methods would be well suited to this task. For example, art appears to have a highly motivating quality for some people living with stroke and traumatic brain injury. Symons et al (2011) observed that some participants felt determined to persist in their creative endeavours despite their functional limitations. Their use of the affected limb improved and some successfully made adaptations to their style, technique or media to accommodate their disabilities. But Beesley et al (2011) described some participants in a group art program as struggling to use the affected limb to their satisfaction, and observed that the cognitive 
demands of the program also led to some clients withdrawing. Wald (1999) pointed out that a range of accessible techniques such as collage needs to be available to facilitate stroke survivors' participation in art-making, as well as adapted equipment such as large-handled brushes. Such adaptations may be helpful not only in enabling stroke survivors to participate in art therapy but to encourage further development of artistic interests outside the art therapy context, which may be helpful for restoring positive identity. Further research incorporating interviews with art therapy clients about the adaptations they have made themselves or found most helpful for enabling participation in art-making would be particularly helpful for tailoring art therapy practice to stroke survivors.

According to Wald (1999) and other authors, stroke survivors who engaged in art (or other creative activities) before their stroke, may be fearful that their disabilities will impact negatively on their standards of artwork. Arts therapists and arts facilitators need sensitivity to these barriers to participation. Further research is needed into the experiential process of art-making in therapy and the turning points that patients themselves identify in reclaiming identity and adapting to disability. Again, in-depth interviews with participants, to complement the reflective accounts of art therapists, would provide a better understanding of the art therapy process as experienced by stroke survivors.

Art-making may offer feelings of temporary escape from the experience of stroke, through for example, immersion in the process and flow. Such experiences are thought to render disability less salient, enhancing the person's sense of autonomy, identity and ability to resist stigma. The experience of flow during leisure-based art-making has been beneficial according to some people living with cancer (Reynolds \& Prior 2006). Further enquiry into stroke survivors' experiences of immersion and flow is needed to complement existing accounts by therapists. 
Through experiencing meaningful self-expression in art therapy, some stroke survivors take up art-making as a new leisure occupation following stroke, according to two of the studies reviewed above. The discovery of meaningful new leisure pursuits would seem to offer the stroke survivor the promise of ongoing personal development and positive hope for the future, despite any residual disabilities. Such participation seems likely to reduce isolation within the community. Studies show that stroke does not necessarily impair creative abilities, even if artistic styles change as a result of right or left-hemisphere lesions. This observation is also borne out by studies of professional artists who have continued their artistic careers following a stroke (Bäzner \& Hennerici, 2006, 2007). Further research is needed into the long-term benefits of engaging in art therapy and whether this experience leads some stroke survivors to engaging in the visual arts as a leisure occupation and thereby gaining a more fulfilling lifestyle, even if their disabilities prevent return to work and other familiar prestroke roles.

\section{References}

Annoni, J., Devuyst, G., Carota, A., Bruggimann, L., Bogousslavsky, J. (2005). Changes in artistic style after minor posterior stroke. Journal of Neurology, Neurosurgery and Psychiatry, 76 (6), 797-803.

Barker, V., Brunk, B. (1991) The role of a creative arts group in the treatment of clients with traumatic brain injury. Music Therapy Perspectives, 9, 26-31.

Bäzner, H. \& Hennerici, M. (2006). Stroke in painters. In F.C. Rose, (Ed.), The neurobiology of painting (pp165-192). London: Academic Press.

Bäzner, H. \& Hennerici, M. (2007). Painting after right-hemisphere stroke: case studies of professional artists. In J. Bogousslavsky, M.G. Hennerici (Eds.), Neurological Disorders in Famous Artists - Part 2 (pp 1-13). Basel: Karger. 
Beesley, K., White, J., Alston, M., Sweetapple, A. \& Pollack, M. (2011). Art after stroke: The qualitative experience of community dwelling stroke survivors in a group art programme. Disability \& Rehabilitation, 33 (22/23), 2346-2355.

Bury, M. (1982). Chronic illness as biographical disruption. Sociology of Health \& Illness, 4 (2), 167-182.

Campbell, M., Fitzpatrick, R., Haines, A., Kinmonth, A., Sandercock, P., Spiegelhalter, D., \& Tyrer, P. (2000). Framework for design and evaluation of complex interventions to improve health. British Medical Journal (BMJ), 321 (7262), 694-696.

Carmi, S. \& Mashiah, T. (1996). Painting as language for a stroke patient. Art Therapy: Journal of the American Art Therapy Association, 13 (4), 265-269.

Csikszentmihalyi, M. (1996). Creativity: flow and the psychology of discovery and invention. New York: Harper Collins.

Dekker, M. (1996). Why oblique and why Jung? In J. Pearson (Ed.), Discovering the Self through Drama and Movement (pp39-45). London: Jessica Kingsley.

Dowswell, D., Lawler, G., Dowswell, J., Young, T., Forster, J., \& Hearn, J. (2000). Investigating recovery from stroke: A qualitative study. Journal of Clinical Nursing, 9 (4), 507-515.

Duncan, P., Wallace, D., Lai, S., Johnson, D., Embretson, S., Laster LJ.(1999). The Stroke Impact Scale Version 2.0: Evaluation of reliability, validity and sensitivity to change. Stroke. 30 (10), 2131-2140.

Ellis-Hill, C., Payne, S., \& Ward, C. (2000). Self-body split: Issues of identity in physical recovery following a stroke. Disability and Rehabilitation, 22, (16), 725-733.

Ferris, B., \& Stein, Y. (2002). Care beyond cancer: The culture of creativity. Illness, Crisis and Loss, 10 (1), 42-50.

Genser, L. (1985). Art as therapy with an aging artist. American Journal of Art Therapy, 23 (3), 93-99. 
Gonen, J. \& Soroker, N. (2000). Art therapy in stroke rehabilitation: A model of short-term group treatment. The Arts in Psychotherapy, 27 (1), 41-50.

Hackett, M., Yapa, C., Parag, V. \& Anderson, C. (2005). Frequency of depression after stroke : A systematic review of observational studies. Stroke, 36 (6),1330-1340.

Hammell, K.W. (2006). Perspectives on disability and rehabilitation: Contesting assumptions; challenging practice. Edinburgh: Churchill-Livingstone.

Hartman-Maeir, A., Soroker, N., Ring, H., Avni, N., \& Katz, N. (2007). Activities, participation and satisfaction one-year post stroke. Disability and Rehabilitation, 29 (7), 559-566.

Hass-Cohen, N. (2008). Partnering of art therapy and clinical neuroscience. In N. HassCohen \& R. Carr, R.(Eds.), Art therapy and clinical neuroscience (pp21-42). London: Jessica Kingsley.

Horovitz, E. (2005). Art therapy as witness: A sacred guide. Springfield, Illinois: Charles C Thomas Publisher.

Johnson, C., \& Sullivan-Marx, E. (2006). Art therapy: Using the creative process for healing and hope among African American older adults. Geriatric Nursing, 27 (5), 309-316.

Jones, F. \& Partridge, C. (2008). The Stroke Self-Efficacy Questionnaire: Measuring individual confidence in functional performance after stroke. Journal of Clinical Nursing, 17 (7b), 244-252.

Jones, P. (2004) The arts therapies: A revolution in health care. Hove: Brunner-Routledge.

Kim, S., Kim, M., Lee, J., \& Chun, S. (2008). Art therapy outcomes in the rehabilitation treatment of a stroke patient: A case report. Art Therapy: Journal of the American Art Therapy Association, 25 (3), 129-133.

Leonard, A. (1993). Art therapy with a left-hemisphere post-stroke patient. In E. Virshup (Ed.), California art therapy trends (pp. 129-139). Chicago: Magnolia Street Publishers. 
Long, J. (2004). Medical art therapy: Using imagery and visual expression in healing. In P.

Camic \& S. Knight (Eds.), Clinical handbook of health psychology: A practical guide to effective interventions (pp. 315-341). Ashland, OH, US: Hogrefe \& Huber Publishers.

Malchiodi, C. (1999) Art therapy and medicine: Powerful partners in healing. In C. Malchiodi, (Ed.), Medical art therapy with adults, (pp 13-24). London: Jessica Kingsley.

Malchiodi, C. (2003). Psychoanalytic, analytic and object relations approaches. In C. Malchiodi (Ed.), Handbook of art therapy (pp. 41-57). New York: The Guilford Press.

McNiff, S. (1992). Art as medicine. Boston: Shambhala.

Michaels, D. (2007). CASE STUDY: The role of art therapy as a potential space for the processing of psychological and physical experience following stroke: Summary of a pilot project - art therapy \& stroke rehabilitation in intermediate care services. Retrieved from www.baat.org/CaseStudyStroke.pdf

Moon, B.L. (2009). Existential art therapy: The canvass mirror. Springfield, Illinois: Charles C Thomas Publisher.

Paolucci, S., Antonucci, G., Grasso, M., Morelli, D., Troisi. E., Coiro, P., \& Bragoni, M. (2000). Early versus delayed inpatient stroke rehabilitation: A matched comparison conducted in Italy. Archives of Physical Medicine \& Rehabilitation, 81 (6), 695-700.

Pedersen, P., Jørgensen, H., Nakayama, H., Raaschou, H., \& Olsen, T. (1995). Aphasia in acute stroke: Incidence, determinants and recovery. Annals of Neurology, 38(4), 659666.

Perruzza, N. \& Kinsella, E. (2010). Creative arts occupations in therapeutic practice: A review of the literature. British Journal of Occupational Therapy, 73(6), 261-268.

Redfern, J., McKevitt, C., \& Wolfe, C. (2006). Development of complex interventions in stroke care: A systematic review. Stroke, 37 (9), 2410-2419. 
Reynolds, F. \& Prior, S. (2006). Creative adventures and flow in art-making: A qualitative study of women living with cancer. British Journal of Occupational Therapy, 69 (6), $255-262$.

Sacchett, C., Byng, S., Marshall, J., \& Pound, C. (1999). Drawing together: Evaluation of a therapy programme for severe aphasia. International Journal of Language and Communication Disorders, 34(3), 265-289.

Sandburg, L., Silver, R., \& Vilstrup, K. (1984). The stimulus drawing technique with adult psychiatric patients, stroke patients, and in adolescent art therapy. Art Therapy, 1 (3), 132-140.

Schaverian, J. (1989). The picture within the frame. In A. Gilroy \& T. Dalley (Eds.), Pictures at an Exhibition: Selected Essays on Art and Art Therapy (pp.147-155). London: Routledge.

Schaverian, J. (1991). The revealing image: Analytical art psychotherapy in theory and practice. London: Routledge.

Sell, M., \& Murrey, G. (2006). Art as a therapeutic modality with TBI populations. In G. Murrey, (Ed.), Alternative therapies in the treatment of brain injury and neurobehavioral disorders: A practical guide (pp. 29-50) New York: Haworth Press.

Silver, R. (1975). Clues to cognitive functioning in the drawings of stroke patients. American Journal of Art Therapy, 15 (10), 3-8.

Silver, R. (2002). Three art assessments techniques: The Silver Drawing Test, Draw-a Story, and Stimulus Drawing. Hove: Brunner-Routledge.

Slayton, S., D’Archer, J., \& Kaplan, F. (2010). Outcome studies on the efficacy of art therapy: A review of findings. Art Therapy: Journal of the American Art Therapy Association, 27(3), 108-118 
Symons, J., Clark, H., Williams, K., Hansen, E., \& Orpin, P. (2011). Visual art in physical rehabilitation: Experience of people with neurological conditions. British Journal of Occupational Therapy, 74 (1), 44-52.

Wald, J. (1989). Severe head injury and its stages of recovery explored through art therapy.

In H. Wadeson, J. Durkin, \& D. Perach (Eds.), Advances in art therapy (pp 181-203). Chichester: John Wiley.

Wald, J. (1999). The role of art therapy in post-stroke rehabilitation, In C. Malchiodi (Ed.), Medical art therapy with adults (pp 25-42). London: Jessica Kingsley.

Wilson, L. (2001). Symbolism and art therapy. In J. Rubin (Ed.), Approaches to art therapy: Theory and technique (pp 40-53). Hove: Brunner-Routledge.

Yaretzky, A., \& Levinson, M. (1996). Clay as a therapeutic tool in group processing with the elderly. American Journal of Art Therapy, 34 (3), 75-82. 